\title{
Positional changes in the mandibular proximal segment after intraoral vertical ramus osteotomy: Surgery-first approach versus conventional approach
}

\author{
Seoyeon Jung ${ }^{\mathrm{a}}$ (1) \\ Yunjin $\mathrm{Choi}^{\mathrm{b}}$ \\ Jung-Hyun Park ${ }^{\mathrm{c}}$ \\ Young-Soo Jung ${ }^{\mathrm{d}}$ \\ Hyoung-Seon Baik ${ }^{e}$
}

${ }^{a}$ Department of Dental Education, Yonsei University College of Dentistry, Seoul, Korea

${ }^{b}$ Department of Statistics, University of Seoul, Seoul, Korea

'Department of Oral and Maxillofacial Surgery, Ewha Womans University Medical Center, Seoul, Korea

${ }^{d}$ Department of Oral and Maxillofacial Surgery, Oral Science Research Center, Yonsei University College of Dentistry, Seoul, Korea

'Department of Orthodontics, Yonsei University College of Dentistry, Seoul, Korea

\begin{abstract}
Objective: To compare postoperative positional changes in the mandibular proximal segment between the conventional orthognathic surgery (CS) and the surgery-first approach (SF) using intraoral vertical ramus osteotomy (IVRO) in patients with Class 111 malocclusion. Methods: Thirty-eight patients with skeletal Class 111 malocclusion who underwent bimaxillary surgery were divided into two groups according to the use of preoperative orthodontic treatment: CS group (n $=18)$ and SF group $(n=20)$. Skeletal changes in both groups were measured using computed tomography before (T0), 2 days after (T1), and 1 year after (T2) the surgery. Three-dimensional (3D) angular changes in the mandibular proximal segment, condylar position, and maxillomandibular landmarks were assessed. Results: The mean amounts of mandibular setback and maxillary posterior impaction were similar in both groups. At T2, the posterior portion of the mandible moved upward in both groups. In the SF group, the anterior portion of the mandible moved upward by a mean distance of $0.9 \pm 1.0 \mathrm{~mm}$, which was statistically significant $(p<0.001)$. There were significant between-group differences in occlusal changes $(p<0.001)$ as well as in overjet and overbite. However, there were no significant between-group differences in proximal segment variables. Conclusions: Despite postoperative occlusal changes, positional changes in the mandibular proximal segment and the position of the condyles were similar between CS and SF, which suggested that SF using IVRO achieved satisfactory postoperative stability. If active physiotherapy is conducted, the proximal segment can be adapted in the physiological position regardless of the occlusal changes.
\end{abstract}

[Korean J Orthod 2020;50(5):324-335]

Key words: Surgery-first approach, Intraoral vertical ramus osteotomy, Computed tomography, Proximal segment

Received February 20, 2020; Revised May 21, 2020; Accepted June 2, 2020.

Corresponding author: Hyoung-Seon Baik.

Honorary Professor, Department of Orthodontics, Yonsei University College of Dentistry, 50-1 Yonsei-ro, Seodaemun-gu, Seoul 03722, Korea.

Tel +82-2-2228-3009 e-mail BAlK@yuhs.ac

How to cite this article: Jung S, Choi Y, Park JH, Jung YS, Baik HS. Positional changes in the mandibular proximal segment after intraoral vertical ramus osteotomy: Surgeryfirst approach versus conventional approach. Korean J Orthod 2020;50:324-335.

(C) 2020 The Korean Association of Orthodontists.

This is an Open Access article distributed under the terms of the Creative Commons Attribution Non-Commercial License (http://creativecommons.org/licenses/by-nc/4.0) which permits unrestricted non-commercial use, distribution, and reproduction in any medium, provided the original work is properly cited. 


\section{INTRODUCTION}

The standard protocol for orthodontic treatment accompanied by orthognathic surgery in patients with skeletal Class 111 malocclusion involves the establishment of stable occlusion through preoperative orthodontic treatment, followed by surgery and postoperative orthodontic treatment. ${ }^{1}$ Recent advances in diagnosis and treatment techniques have resulted in the use of the surgery-first approach (SF), wherein the orthognathic surgery is performed first and subsequently followed by postoperative orthodontic treatment. ${ }^{2}$ Reported advantages of the SF approach are as follows: increased efficiency of tooth movement; an improvement in facial esthetics, which results in increased patient compliance during postoperative orthodontic treatment; and a shorter total treatment duration. ${ }^{2}$ However, there are diverse opinions about the stability and predictability of SF in terms of the final occlusion and mandibular position. This is because the occlusion changes throughout the period of postoperative orthodontic treatment, and the position of the bone segments can also change accordingly. ${ }^{3}$

In particular, the positional relationship between the distal and proximal bone segments can change in patients who undergo intraoral vertical ramus osteotomy (IVRO) for mandibular setback, because this surgery does not fix the segments. ${ }^{4}$ The proximal segment plays an important role in the postoperative recovery of normal jaw function and postoperative stability., ${ }^{5,6}$ The patient generally undergoes active physiotherapy during the bone healing period, and in this process, remodeling takes place at the contact site of bony fragments as well as the surrounding structures. ${ }^{7}$ IVRO has advantages over sagittal split ramus osteotomy (SSRO) in terms of the physiological position of the condyles after surgery, although studies of postoperative stability are fewer for IVRO than for SSRO. ${ }^{8}$

Comparisons of stability between SF and the conventional orthognathic surgery approach (CS) have been reported in a broad spectrum of literature. ${ }^{3,9,10}$ However, there are few studies involving IVRO, with previous research being primarily based on two-dimensional (2D) lateral cephalograms." IVRO allows movement of the bone segments after surgery; therefore, positional changes in the segments during postoperative orthodontic treatment would be different from those after SSRO. Therefore, it is necessary to study the movements of the bone segments after SF using IVRO and consider these changes during treatment planning. Moreover, because evaluation based on 2D images has limited value in this kind of analysis, three-dimensional (3D) assessments using computed tomography (CT) are required.

Accordingly, the aim of this study was to use 3D CT analysis to compare postoperative positional changes in the mandibular proximal segment, which might affect postoperative stability, between CS and SF using IVRO in patients with Class 111 maloccusion.

\section{MATERIALS AND METHODS}

\section{Subjects and surgical methodology}

Thirty-eight patients who underwent bimaxillary orthognathic surgery performed by the same surgeon in the Department of Oral and Maxillofacial Surgery at Yonsei University Dental Hospital from 2010 through 2014 were recruited. The inclusion criteria were as follows: diagnosis of skeletal Class 111 malocclusion; menton deviation within $3 \mathrm{~mm}$ of the midsagittal plane (MSP); requirement of nonextraction orthodontic treatment; and availability of preoperative, immediate postoperative, and 1-year postoperative multi-detector CT records obtained under informed consent. The exclusion criteria were as follows: menton deviation over $3 \mathrm{~mm}$, cleft lip and palate or other severe maxillofacial congenital deformities, and metabolic diseases that could affect the bone healing process. The subjects were divided into two groups according to the use of preoperative orthodontic treatment. Eighteen patients (10 male and 8 female patients; average age, $20.1 \pm 2.6$ years) received orthodontic treatment before the orthognathic surgery (CS group; control), while 20 patients (12 male and 8 female patients; average age, $20.3 \pm 2.4$ years) did not receive orthodontic treatment before the orthognathic surgery (SF group). All subjects underwent Le Fort 1 osteotomy and mandibular setback surgery using IVRO. During surgery, the maxilla was fixed using metal plates, and the masseter, pterygomandibular sling, and medial pterygoid muscles, which are attached to the mandible, were extensively detached. Intermaxillary fixation was performed with the cortical bone of the external area of the distal bone segment and the internal area of the proximal bone segment remaining in contact without rigid fixation. All patients underwent 5 weeks of active physiotherapy after removal of the fixation followed by postoperative orthodontic treatment.

This restrospective cohort study followed the Declaration of Helsinki on medical protocol and ethics, and was approved by Yonsei University Dental Hospital Institutional Review Board (IRB No.2-2016-0004).

\section{Three-dimensional analysis}

CT images (SOMATOM Definition AS; Siemens, Erlangen, Germany) were obtained and evaluated before (T0), 2 days after (T1), and 1 year after (T2) the surgery for all patients. Images were acquired under the following conditions: $120 \mathrm{~mA}, 100 \mathrm{kV}$, scanning time of 1 second, slice thickness of $0.6 \mathrm{~mm}$, and field of view of $24.1 \mathrm{~cm}$. 
Mimics 16.0 (Materialise NV, Leuven, Belgium), a 3D medical image program, was used to reconstruct the 3D images as stereolithography (STL) files and separate the reconstructed mandible from the skull for accurate measurement of condylar reference points. The 3D cranial models were superimposed using the Rapidform 2006 (INUS Technology, Seoul, Korea) program at T0, T1, and T2, so that all measurements were obtained using a common reference plane. Guiding points, including the two supraorbital foramina, two zygomaticofacial foramina, and lambda point (Figure 1), were used for the overlapping process, with an error of $<0.2 \mathrm{~mm}$ (Figure 1B).

Simplant ${ }^{\circledR}$ software (Materialise NV) was used for 3D analysis. Descriptions of the landmark points and reference planes are presented in Table 1 and Figure 2. The MSP was established according to the method of Park et al. ${ }^{12}$ and point $\mathrm{P}$ was determined as shown in Figure 1C. All points were distributed in the same direction toward the reference planes.

In the maxilla, the anterior representative points were $\mathrm{U} 1$ and $\mathrm{A}$ points, while the posterior representative point was PNS (see Table 1 for definitions). For measurement of dental movements, the palatal cusp tip of the maxillary second molar was used. The amount of mandibular displacement was measured using the mid-MF point and point $\mathrm{B}$ as the anterior representative points and point $\mathrm{F}$ as the posterior representative point (Table 1, Figure 3A). All points were unchanged structures and highly reproducible points on the $3 \mathrm{D}$ reconstructed images. The distances between reference planes and points were measured.
The landmark points and plane of the mandibular proximal segment are presented in Table 1 and Figure 3B. Positional changes from $\mathrm{T} 0$ to $\mathrm{T} 1$ (T1-T0) and $\mathrm{T} 1$ to T2 (T2-T1) were evaluated from two perspectives: positional changes in three planes and movement of the uppermost point on the condyle (CON). For measurement of proximal segment displacement in the coronal plane, a line passing through $\mathrm{Cp}$ and Go-post was projected onto the coronal plane. Then, the angle between the line and a line created by the horizontal plane being projected on the coronal plane was measured. The same method was applied for the sagittal and horizontal planes. A positive value was assigned when the proximal segment rotated laterally from MSP, clockwise in the sagittal plane, and outward from MSP in the horizontal plane (Figure 4). For the assessment of condylar head displacement, mediolateral, anteroposterior, and vertical displacements of CON were measured at T0, T1, and T2. For measurement of the angular change between the proximal and distal segments, the angle between the proximal segment plane (PxP) and the mandibular plane (MP) was separately measured on the right and left sides.

\section{Statistical analyses}

All measurements were performed twice, with a 1-week interval between measurements, by one trained observer (SJ). According to the paired t-test, there was no significant difference between measurements at the two time points. All statistical analyses were performed using IBM SPSS Statistics for Windows, version 23.0 (IBM Co., Armonk, NY, USA). A $p$-value of $<0.05$ was consid-
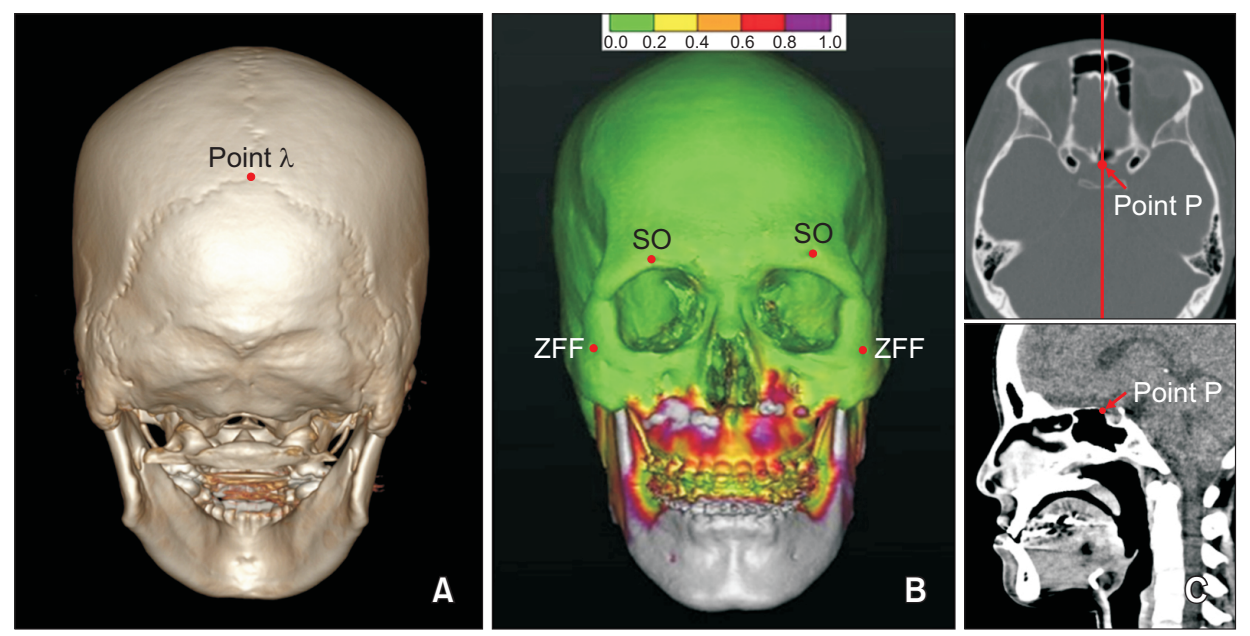

Figure 1. Landmark points used for superimposition of three-dimensional computed tomography images and point $P$. A, Lambda point. B, The image shows evaluation of the accuracy of superimposition using a color diagram. Errors within

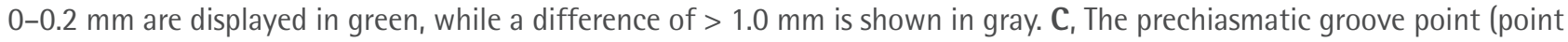
$\mathrm{P}$, The vertical and transverse midpoint of prechiasmatic groove).

SO, Supraorbital foramen; ZFF, zygomaticofacial foramen. 
Table 1. Description of reference planes and landmark points

\begin{tabular}{|c|c|}
\hline Landmark & Description \\
\hline \multicolumn{2}{|l|}{ Landmark points } \\
\hline Porion (Po) & The highest midpoint on the roof of external auditory meatus \\
\hline Orbitale (Or) & The lowest point on the infraorbital margin of each orbit (bilateral) \\
\hline Nasion (Na) & $\begin{array}{l}\text { The junction of the frontal nasal suture at the most posterior on the curve at the bridge } \\
\text { of the nose }\end{array}$ \\
\hline Point prechiasmatic groove $(\mathrm{P})$ & The vertical and transverse midpoint of prechiasmatic groove \\
\hline Mid-Po & The midpoint of the right and left porions \\
\hline U1 & The midpoint of incisal tip of the right upper incisor \\
\hline A point & Innermost curvature from maxillary anterior nasal spine to crest of alveolar process \\
\hline PNS & Posterior nasal spine \\
\hline$\# 17$ & Palatal cusp tip of the right maxillary second molar \\
\hline$\# 27$ & Palatal cusp tip of the left maxillary second molar \\
\hline Mental foramen (MF) & $\begin{array}{l}\text { A foramen which transmits the terminal branches of the inferior alveolar nerve and } \\
\text { vessels. The most anterior point of mental foramen is defined as MF }\end{array}$ \\
\hline Mid-MF & The midpoint of the right and left MFs \\
\hline Mandibular foramen $(\mathrm{F})$ & $\begin{array}{l}\text { A foramen passing through the mandibular nerve and vessels. The most inferior point } \\
\text { of mandibular foramen is defined as } F\end{array}$ \\
\hline Medial condylar head point (MCP) & The most medial point of the condylar head \\
\hline Lateral condylar head point (LCP) & The most lateral point of the condylar head \\
\hline $\mathrm{Cp}$ & The most prominent posterior point of condyle \\
\hline Go-post & The most prominent posterior point of ramus posterior border \\
\hline $\mathrm{CON}$ & The most superior point of condylar head \\
\hline \multicolumn{2}{|l|}{ Reference planes } \\
\hline Horizontal plane (FH plane) & The plane constructed by Right-Po, Left-Po, Left-Or \\
\hline Midsagittal plane (MSP) & The plane constructed by Na, point $\mathrm{P}$, and normal to $\mathrm{FH}$ plane \\
\hline Coronal plane & The plane normal to MSP, FH plane passing through mid-Po \\
\hline Mandibular plane (MP) & A plane through point Right-F, Left-F and mid-MF \\
\hline Proximal segment plane (PxP) & A plane through point $\mathrm{Cp}$, Go-post and normal to MSP \\
\hline
\end{tabular}

ered statistically significant. The independent $t$-test was used to detect significant differences between the CS and SF groups, and the paired $t$-test was used to detect changes in the measurements during each time interval. Mixed model repeated measures analysis of variance was performed to detect statistically significant betweengroup differences in changes in the mandibular proximal segment during $\mathrm{T} 1-\mathrm{T} 0$ and $\mathrm{T} 2-\mathrm{T} 1$.

\section{RESULTS}

There were no significant between-group differences in parameters measured on the initial lateral cephalograms, with the exception of Wits appraisal (Table 2). The average duration of preoperative orthodontic treatment in the CS group was 14.5 months, whereas the SF group had an average preparation period of 4.2 weeks before the orthognathic surgery. In the CS group, IMPA increased from $80.3^{\circ} \pm 4.0^{\circ}$ to $85.3^{\circ} \pm 4.6^{\circ}$ because of decompensation of the mandibular anterior teeth $(p=$ 0.02).

Two days after the surgery, the amount of mandibular setback at the mid-MF point was $7.9 \pm 3.9 \mathrm{~mm}$ in the CS group and $8.0 \pm 4.2 \mathrm{~mm}$ in the SF group (Table 3). Surgical changes in the maxilla and mandible did not show significant differences between the two groups. In the mandible, the amount of horizontal movement was larger than the amount of vertical movement at the anterior portion. However, in accordance with the amount of maxillary posterior impaction, vertical movement was dominant at the posterior portion of the mandible, which was represented by point $F$.

Skeletal and dental changes were measured at 1 year after the surgery (T2-T1). The A point had moved up- 


\section{Kرo}

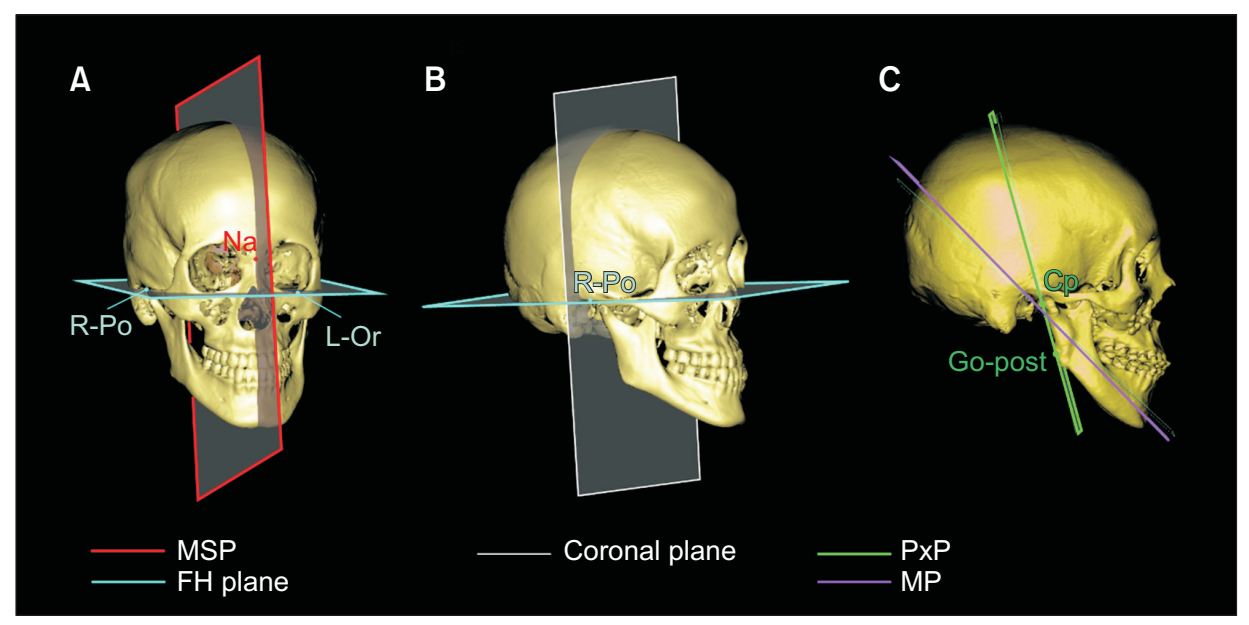

Figure 2. Construction of the co-ordinate system and reference planes. A, Horizontal plane (FH plane) and midsagittal plane (MSP). B, Coronal plane and FH plane. C, Proximal segment plane (PxP) and mandibular plane (MP).

$\mathrm{R}-\mathrm{Po}$, Right porion (the highest midpoint on the roof of external auditory meatus); L-Or, left orbitale (the lowest point on the infraorbital margin of each orbit); $\mathrm{Na}$, nasion (the junction of the frontal nasal suture at the most posterior on the curve at the bridge of the nose); Go-post, the most prominent posterior point of ramus posterior border; $\mathrm{Cp}$, the most prominent posterior point of condyle.
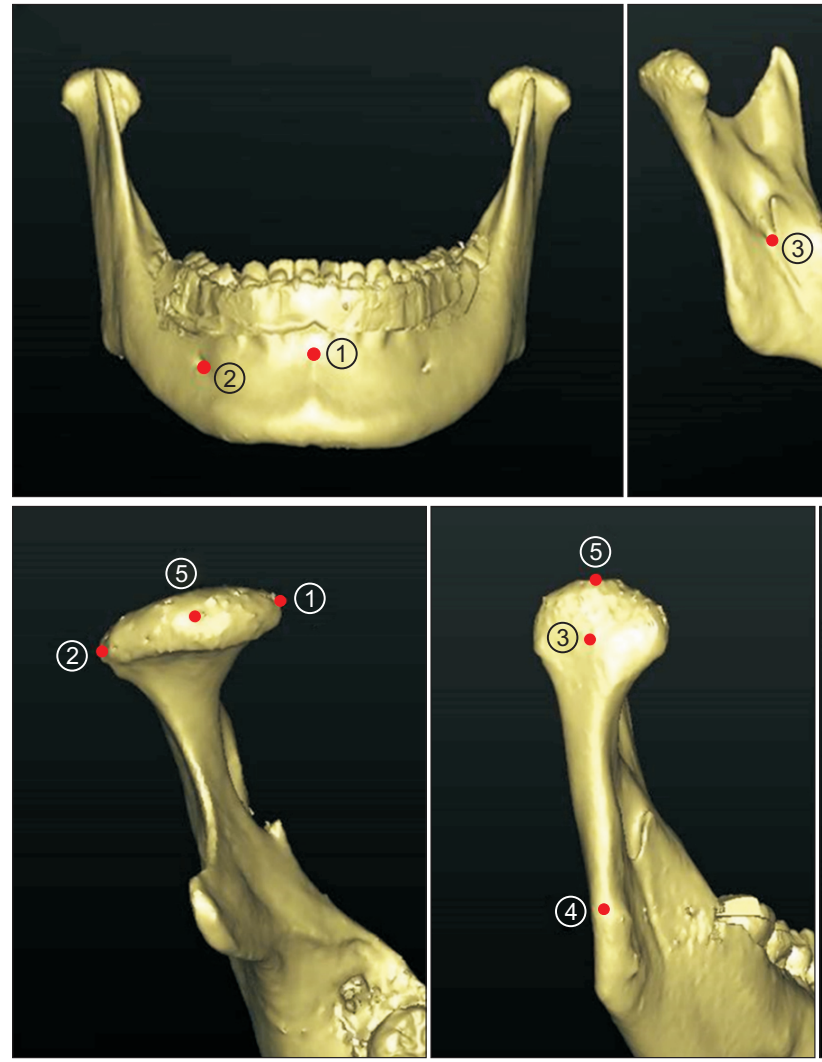

ward by $0.4 \pm 0.6 \mathrm{~mm}$ in the CS group with statistical significance $(p<0.05)$; whereas $0.0 \pm 0.7 \mathrm{~mm}$ movement in the SF group ( $p=1.000)$, however, there was no significant between-group difference ( $p=0.066$; Table
Figure 3. Landmark points for the mandibular segments. A, Distal segment. (1) B point; (2) MF, mental foramen; (3) $\mathrm{F}$, mandibular foramen. $\mathrm{B}$, Proximal segment. (1) MCP, Medial condylar head point; (2) LCP, lateral condylar head point; (3) $\mathrm{Cp}$, the most prominent posterior point of condyle; (4) Go-post, the most prominent posterior point of ramus posterior border; (5) CON, uppermost point on the condyle.
4). No significant vertical or anteroposterior movement of PNS was observed in either group. The amount of maxillary second molar intrusion on the right and left sides in the SF group was $1.2 \pm 0.6 \mathrm{~mm}$ and $1.3 \pm 0.5$ 

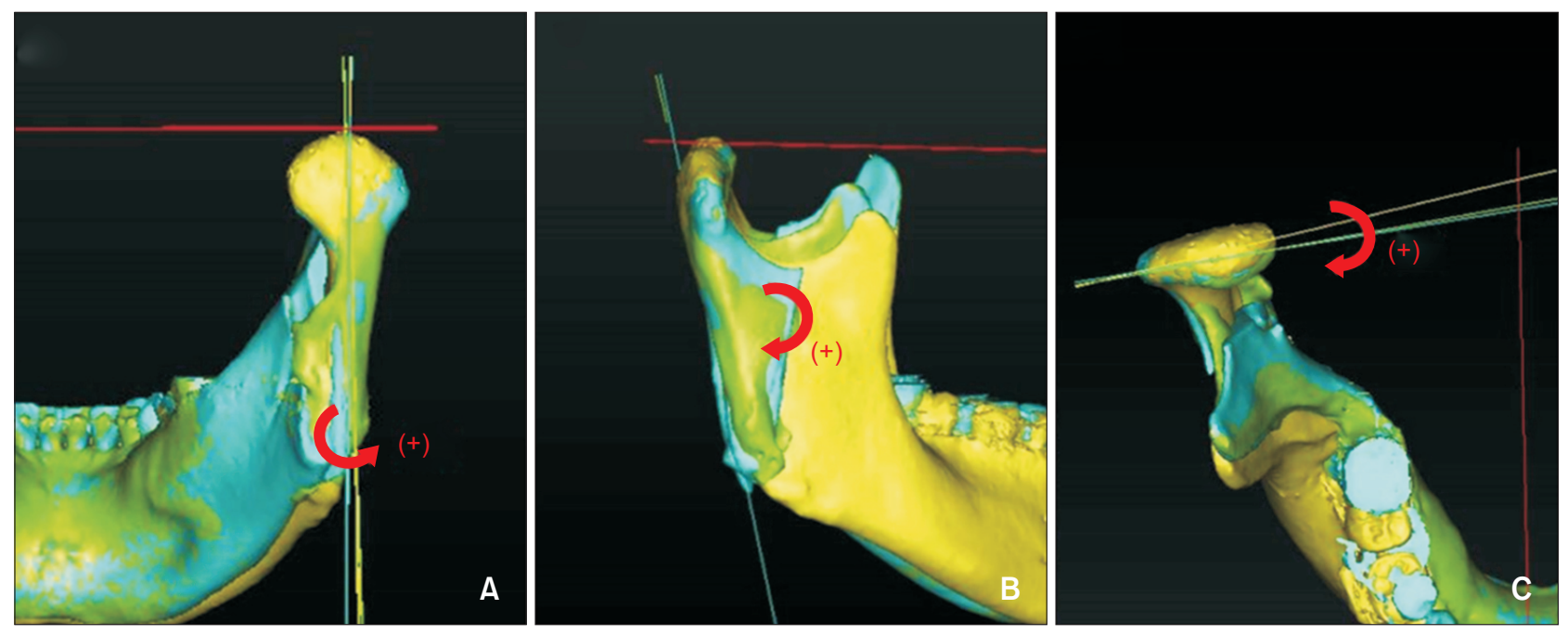

Figure 4. Evaluation of positional changes in the mandibular proximal segment after surgery. $\mathrm{A}$, Coronal change. $(+)$, Lateral flaring from the midsagittal plane (MSP). B, Sagittal change. (+), Clockwise rotation. C, Horizontal change. $(+)$, Outward rotation from MSP.

Table 2. Initial cephalometric characteristics of patients in the CS and SF groups

\begin{tabular}{lccc}
\hline Lateral cephalometric variable & CS group $(\mathbf{n}=\mathbf{1 8})$ & SF group $(\mathbf{n}=\mathbf{2 0})$ & Between groups \\
\hline SNA $\left(^{\circ}\right)$ & $80.0 \pm 3.0$ & $79.2 \pm 3.6$ & $\boldsymbol{p}$-value \\
\hline SNB $\left(^{\circ}\right)$ & $82.3 \pm 3.2$ & $83.0 \pm 2.9$ & 0.464 \\
ANB $\left(^{\circ}\right)$ & $-2.3 \pm 1.2$ & $-3.0 \pm 1.7$ & 0.484 \\
Wits $(\mathrm{mm})$ & $-9.9 \pm 3.4$ & $-13.0 \pm 1.9$ & 0.155 \\
FH-PP $\left(^{\circ}\right)$ & $3.0 \pm 1.8$ & $2.5 \pm 1.7$ & $0.001^{* *}$ \\
FH-OP $\left(^{\circ}\right)$ & $9.9 \pm 4.3$ & $9.4 \pm 2.5$ & 0.384 \\
FH-MP $\left(^{\circ}\right)$ & $38.1 \pm 5.8$ & $36.6 \pm 5.6$ & 0.660 \\
U1 to SN $\left(^{\circ}\right)$ & $108.2 \pm 7.4$ & $108.8 \pm 5.3$ & 0.423 \\
IMPA $\left(^{\circ}\right)$ & $80.3 \pm 4.0$ & $80.3 \pm 4.3$ & 0.774 \\
Overjet $(\mathrm{mm})$ & $-2.0 \pm 2.3$ & $-3.0 \pm 3.0$ & 1.000 \\
Overbite $(\mathrm{mm})$ & $-0.8 \pm 2.2$ & $-0.3 \pm 2.1$ & 0.260 \\
\hline
\end{tabular}

Values are presented as mean \pm standard deviation.

Independent $t$-test was performed.

CS, Conventional orthognathic surgery approach; SF, surgery-first approach; SNA, sella-nasion-A point angle; SNB, sellanasion-B point angle; ANB, A point-nasion-B point angle; FH, Frankfort horizontal plane; PP, palatal plane; OP, occlusal plane; MP, mandibular plane; U1 to SN, angle between the long axis of the maxillary incisor and sella-nasion line; IMPA, angle between the long axis of the mandibular incisor and mandibular plane.

** $p<0.01$.

$\mathrm{mm}$, respectively, with a significant between-group difference $(p<0.001)$. Although the vertical movement of U1 showed no significant difference between the different time points in each group, there was a statistically significant difference between the two groups $(p<0.05)$.
The mandibular foramen (F) moved superiorly in both groups. The mid-MF point, which represented the anterior portion of the mandible, moved upward by a mean \pm SD amount of $0.9 \pm 1.0 \mathrm{~mm}$ in the SF group with statistical significance $(p<0.001)$, and $0.5 \pm 1.2 \mathrm{~mm}$ in the 
Table 3. Three-dimensional changes in the maxilla and mandible from before surgery to 2 days after surgery in the CS and SF groups

\begin{tabular}{lccc}
\hline Variable & CS group & SF group & Between groups \\
\cline { 4 - 4 } Anteroposterior movement $(\mathrm{mm})$ & & & p-value \\
Maxilla & & & \\
U1 & $-0.4 \pm 1.5$ & $-0.5 \pm 2.6$ & 0.887 \\
A point & $1.2 \pm 1.5$ & $1.3 \pm 3.0$ & 0.899 \\
PNS & $-0.9 \pm 1.8$ & $-1.3 \pm 1.1$ & 0.409 \\
Mandible & & & \\
Mid-MF & $-7.9 \pm 3.9$ & $-8.0 \pm 4.2$ & 0.940 \\
B point & $-7.4 \pm 3.8$ & $-7.6 \pm 4.0$ & 0.876 \\
Rt. F & $-5.3 \pm 4.5$ & $-6.4 \pm 4.3$ & 0.446 \\
Lt. F & $-5.6 \pm 3.6$ & $-6.4 \pm 4.4$ & 0.546 \\
OJ & $5.0 \pm 4.0$ & $6.2 \pm 3.7$ & 0.343 \\
Vertical movement $(\mathrm{mm})$ & & & \\
Maxilla & & & 1.000 \\
U1 & $-0.4 \pm 1.7$ & $-0.4 \pm 1.4$ & 0.409 \\
A point & $-0.9 \pm 1.8$ & $-1.3 \pm 1.1$ & 0.398 \\
PNS & $-4.5 \pm 2.0$ & $-4.0 \pm 1.6$ & \\
Mandible & & & 0.220 \\
Mid-MF & $-4.0 \pm 1.7$ & $-3.1 \pm 2.6$ & 0.822 \\
B point & $-3.0 \pm 2.5$ & $-2.8 \pm 2.9$ & 0.541 \\
Rt. F & $-6.3 \pm 3.2$ & $-5.7 \pm 2.8$ & 0.051 \\
Lt. F & $-6.9 \pm 3.2$ & $-5.0 \pm 2.6$ & 0.158 \\
OB & $1.6 \pm 2.6$ & $0.5 \pm 2.1$ & \\
\hline
\end{tabular}

Values are presented as mean \pm standard deviation.

Independent $t$-test was performed.

CS, Conventional orthognathic surgery approach; SF, surgery-first approach; Rt., right; Lt., left; OJ, overjet; OB, overbite; (+), forward/downward movement; (-), backward/upward movement.

See Table 1 for definitions of the other landmarks.

CS group with no significance ( $p=0.094)$. There was no statistically significant difference found in the changes between the two groups. It seems the corresponding effect sizes are comparable to one another. The B point moved backward by $0.8 \pm 1.3$ and $0.9 \pm 1.3 \mathrm{~mm}$ in the CS and SF groups, respectively.

Overjet exhibited a significant decrease of $0.9 \pm 1.3$ $\mathrm{mm}$ in the SF group while overbite increased by $0.4 \pm$ $0.6 \mathrm{~mm}$ in the CS group and $1.5 \pm 0.8 \mathrm{~mm}$ in the SF group with a significant difference between groups $(p<$ 0.001). The PxP and MP increased by $9.1^{\circ} \pm 4.5^{\circ}$ in the CS group and $6.2^{\circ} \pm 5.2^{\circ}$ in the SF group, respectively ( $p$ $<0.001$ ) at 1 year after the surgery.

In both groups, the mandibular proximal segment flared laterally from MSP, with clockwise rotation in the sagittal plane and outward rotation from MSP in the horizontal plane immediately after the surgery (Table 5). Figure 5 presents the tendency for recovery to the preoperative position after 1 year of surgery for both groups. The scores for T2-T1 indicated that this tendency was statistically significant in terms of the coronal, sagittal, and horizontal planes. When the independent $t$-test was performed for the time intervals of $\mathrm{T} 1-\mathrm{T} 0$, $\mathrm{T} 2-\mathrm{T} 1$, and $\mathrm{T} 2-\mathrm{T} 0$, there were no statistically significant between-group differences in the angular changes on any plane. In addition, mixed model repeated measures analysis of variance (ANOVA) found no significant differences on all three planes throughout the observation period (Table 5). This can be empirically observed from the graphical display in Figure 5. The ANOVA score corresponding to the T2-T0 interval are not included because the score is the sum of the scores for T1-T0 and 
Table 4. Three-dimensional changes in the maxilla and mandible from 2 days after surgery to 1 year after surgery in the CS and SF groups

\begin{tabular}{|c|c|c|c|c|c|}
\hline \multirow{2}{*}{ Variable } & \multicolumn{2}{|c|}{ CS group } & \multicolumn{2}{|c|}{ SF group } & \multirow{2}{*}{$\begin{array}{c}\begin{array}{c}\text { Between } \\
\text { groups }\end{array} \\
p \text {-value }\end{array}$} \\
\hline & Mean \pm SD & $p$-value & Mean \pm SD & $p$-value & \\
\hline \multicolumn{6}{|c|}{ Anteroposterior movement (mm) } \\
\hline \multicolumn{6}{|l|}{ Maxilla } \\
\hline A point & $-1.1 \pm 0.8^{* * *, \dagger}$ & 0.000 & $-1.3 \pm 0.9^{* * *, \dagger}$ & 0.000 & 0.473 \\
\hline PNS & $-0.7 \pm 1.7$ & 0.098 & $-0.4 \pm 1.0$ & 0.089 & 0.519 \\
\hline \multicolumn{6}{|l|}{ Mandible } \\
\hline Mid-MF & $-0.6 \pm 1.5$ & 0.107 & $-0.5 \pm 1.5$ & 0.152 & 0.839 \\
\hline B point & $-0.8 \pm 1.3^{*, \dagger}$ & 0.018 & $-0.9 \pm 1.3^{* *, \dagger}$ & 0.006 & 0.814 \\
\hline Rt. F & $0.7 \pm 2.2$ & 0.194 & $0.9 \pm 2.5$ & 0.123 & 0.795 \\
\hline Lt. F & $0.3 \pm 2.3$ & 0.587 & $1.3 \pm 2.3^{*, \dagger}$ & 0.020 & 0.189 \\
\hline OJ & $0.1 \pm 1.1$ & 0.704 & $-0.9 \pm 1.3^{* *, \dagger}$ & 0.006 & $0.015^{*}$ \\
\hline \multicolumn{6}{|c|}{ Vertical movement (mm) } \\
\hline \multicolumn{6}{|c|}{ Maxilla } \\
\hline A point & $-0.4 \pm 0.6^{*, \dagger}$ & 0.011 & $0.0 \pm 0.7$ & 1.000 & 0.066 \\
\hline PNS & $0.1 \pm 0.7$ & 0.552 & $-0.1 \pm 0.6$ & 0.465 & 0.354 \\
\hline \multicolumn{6}{|l|}{ Mandible } \\
\hline Mid-MF & $-0.5 \pm 1.2$ & 0.094 & $-0.9 \pm 1.0^{* * *, \dagger}$ & $<0.001$ & 0.275 \\
\hline B point & $-0.4 \pm 1.0$ & 0.107 & $-0.3 \pm 1.2$ & 0.277 & 0.781 \\
\hline Rt. F & $-1.5 \pm 1.7^{* *,+}$ & 0.002 & $-1.8 \pm 1.9^{* * *, \dagger}$ & 0.000 & 0.611 \\
\hline Lt. F & $-1.4 \pm 1.5^{* *,+}$ & $<0.001$ & $-2.2 \pm 2.6^{* *,+}$ & 0.001 & 0.249 \\
\hline OB & $0.4 \pm 0.6^{*, \dagger}$ & 0.011 & $1.5 \pm 0.8^{* * *, \dagger}$ & 0.000 & $0.000^{* * *}$ \\
\hline \multicolumn{6}{|c|}{ Vertical dental movement (mm) } \\
\hline U1 & $-0.2 \pm 0.5$ & 0.107 & $0.2 \pm 0.6$ & 0.152 & $0.031^{*}$ \\
\hline$\# 17$ & $0.1 \pm 0.7$ & 0.552 & $-1.2 \pm 0.6^{* * *, \dagger}$ & 0.000 & $0.000^{* * *}$ \\
\hline \#27 & $-0.2 \pm 0.6$ & 0.174 & $-1.3 \pm 0.5^{* * *, \dagger}$ & 0.000 & $0.000^{* * *}$ \\
\hline \multicolumn{6}{|c|}{ Angular change $\left({ }^{\circ}\right)$} \\
\hline FH-MP & $1.9 \pm 2.8^{*, \dagger}$ & 0.010 & $1.5 \pm 2.6^{*, \dagger}$ & 0.018 & 0.652 \\
\hline PxP-MP & $9.1 \pm 4.5^{* * *, \dagger}$ & 0.000 & $6.2 \pm 5.2^{* * *, \dagger}$ & 0.000 & 0.074 \\
\hline
\end{tabular}

CS, Conventional orthognathic surgery; SF, surgery-first approach; SD, standard deviation; Rt., right; Lt., left; OJ, overjet; OB, overbite; FH-MP, angle between the Frankfort horizontal plane and the mandibular plane; PxP-MP, angle between the proximal segment plane and mandibular plane; (+), forward/downward movement; (-), backward/upward movement. ${ }^{*} p<0.05,{ }^{* *} p<0.01,{ }^{* * *} p<0.001$. Independent $t$-test or $^{\dagger}$ paired $t$-test were performed. See Table 1 for definitions of the other landmarks.

T2-T1. Sphericity correction was not applied because the number of groups and number of sections, which were both two, yielded a correction coefficient of 1, which is equivalent to the original scale.

In the coronal plane, the line passing through $\mathrm{Cp}$ and Go-post showed a tendency to flare laterally from MSP after surgery, with flaring of $6.1^{\circ} \pm 3.6^{\circ}$ in the CS group and $6.5^{\circ} \pm 3.9^{\circ}$ in the SF group (see Figure 4 for de- scriptions of the directions). At 1 year after surgery, the line showed a tendency to recover by moving $27.7 \%$ and $31.3 \%$ medially in the CS and SF groups, respectively, with no significant between-group difference. In the sagittal plane, the line passing through $\mathrm{Cp}$ and G-Post showed clockwise rotation of $8.2^{\circ} \pm 4.4^{\circ}$ and $8.8^{\circ} \pm$ $3.6^{\circ}$ after surgery in the CS and SF groups, respectively. Moreover, the line showed counterclockwise rotation of 
Table 5. Angular changes in the proximal segment from before surgery (T0) to 2 days (T1) and 1 year after surgery (T2) in the CS and SF groups, analyzed using mixed model repeated measures ANOVA

\begin{tabular}{|c|c|c|c|c|c|c|}
\hline \multirow{2}{*}{\multicolumn{2}{|c|}{ Variable }} & \multicolumn{2}{|c|}{ CS group } & \multicolumn{2}{|c|}{ SF group } & \multirow{3}{*}{$\begin{array}{c}\text { Between groups } \\
\text { p-value }^{\dagger} \\
0.645\end{array}$} \\
\hline & & \multirow{2}{*}{$\begin{array}{r}\text { Mean } \pm \text { SD } \\
6.1 \pm 3.6^{* * *, \S}\end{array}$} & \multirow{2}{*}{$\begin{array}{c}p \text {-value } \\
0.000\end{array}$} & \multirow{2}{*}{$\begin{array}{r}\text { Mean } \pm \text { SD } \\
6.5 \pm 3.9^{* * *, \S}\end{array}$} & \multirow{2}{*}{$\begin{array}{c}p \text {-value } \\
0.000\end{array}$} & \\
\hline $\operatorname{COR}\left(^{\circ}\right)$ & T1-T0 & & & & & \\
\hline & $\mathrm{T} 2-\mathrm{T} 1$ & $-1.7 \pm 2.1^{* * *, \S}$ & 0.000 & $-2.1 \pm 2.3^{* * *, \S}$ & 0.000 & 0.433 \\
\hline & T2-T0 & $4.4 \pm 3.2^{* * *, \S}$ & 0.000 & $4.5 \pm 3.1^{* * *, \S}$ & 0.000 & 0.890 \\
\hline \multirow[t]{3}{*}{$\mathrm{SAG}\left({ }^{\circ}\right)$} & T1-T0 & $8.2 \pm 4.4^{* * *, \S}$ & 0.000 & $8.8 \pm 3.6^{* * *, \S}$ & 0.000 & 0.516 \\
\hline & $\mathrm{T} 2-\mathrm{T} 1$ & $-5.7 \pm 4.8^{* * *, \S}$ & 0.000 & $-5.8 \pm 3.8^{* * *, \S}$ & 0.000 & 0.920 \\
\hline & T2-T0 & $2.5 \pm 4.5^{* *, \S}$ & 0.002 & $3.0 \pm 4.3^{* * *, \S}$ & 0.000 & 0.622 \\
\hline \multirow[t]{3}{*}{$\operatorname{HOR}\left(^{\circ}\right)$} & T1-T0 & $9.4 \pm 5.4^{* * *, \S}$ & 0.000 & $10.5 \pm 6.0^{* * *, \S}$ & 0.000 & 0.406 \\
\hline & $\mathrm{T} 2-\mathrm{T} 1$ & $-4.1 \pm 3.2^{* * *, \S}$ & 0.000 & $-3.1 \pm 4.5^{* * *, \S}$ & 0.000 & 0.273 \\
\hline & $\mathrm{T} 2-\mathrm{T} 0$ & $5.3 \pm 4.4^{* * *, \S}$ & 0.000 & $7.3 \pm 4.1^{* * *, \S}$ & 0.000 & 0.054 \\
\hline ANOVA & \multicolumn{2}{|c|}{ Source of variance } & SS & MS & $\mathbf{F}$ & $p$-value ${ }^{\neq}$ \\
\hline \multirow[t]{2}{*}{ COR } & \multicolumn{2}{|c|}{ Between group } & 0.04 & 0.04 & 0.004 & 0.95 \\
\hline & \multicolumn{2}{|c|}{ Subjects within group } & 369.123 & 10.004 & & \\
\hline \multirow[t]{2}{*}{ SAG } & \multicolumn{2}{|c|}{ Between group } & 2.228 & 2.228 & 0.115 & 0.736 \\
\hline & \multicolumn{2}{|c|}{ Subjects within group } & 696.995 & 19.361 & & \\
\hline \multirow[t]{2}{*}{ HOR } & \multicolumn{2}{|c|}{ Between group } & 38.465 & 38.465 & 2.144 & 0.152 \\
\hline & \multicolumn{2}{|c|}{ Subjects within group } & 645.764 & 17.938 & & \\
\hline
\end{tabular}

CS, Conventional orthognathic surgery; SF, surgery-first approach; ANOVA, analysis of variance; SD, standard deviation; COR, angular changes in the proximal segment in the coronal view: (+) lateral flaring from midsagittal plane (MSP), (-) medial flaring from MSP; SAG, angular changes in the sagittal view: (+) clockwise rotation, (-) counterclockwise rotation; HOR, angular changes in the horizontal view: (+) outward rotation, (-) inward rotation; SS, sum of squares; MS, mean squares; F, test statistic.

${ }^{* * *} p<0.001$.

${ }^{\dagger}$ Two-sample $t$-test.

${ }^{\dagger}$ Mixed model repeated measures ANOVA.

${ }^{\varsigma}$ Paired $t$-test.
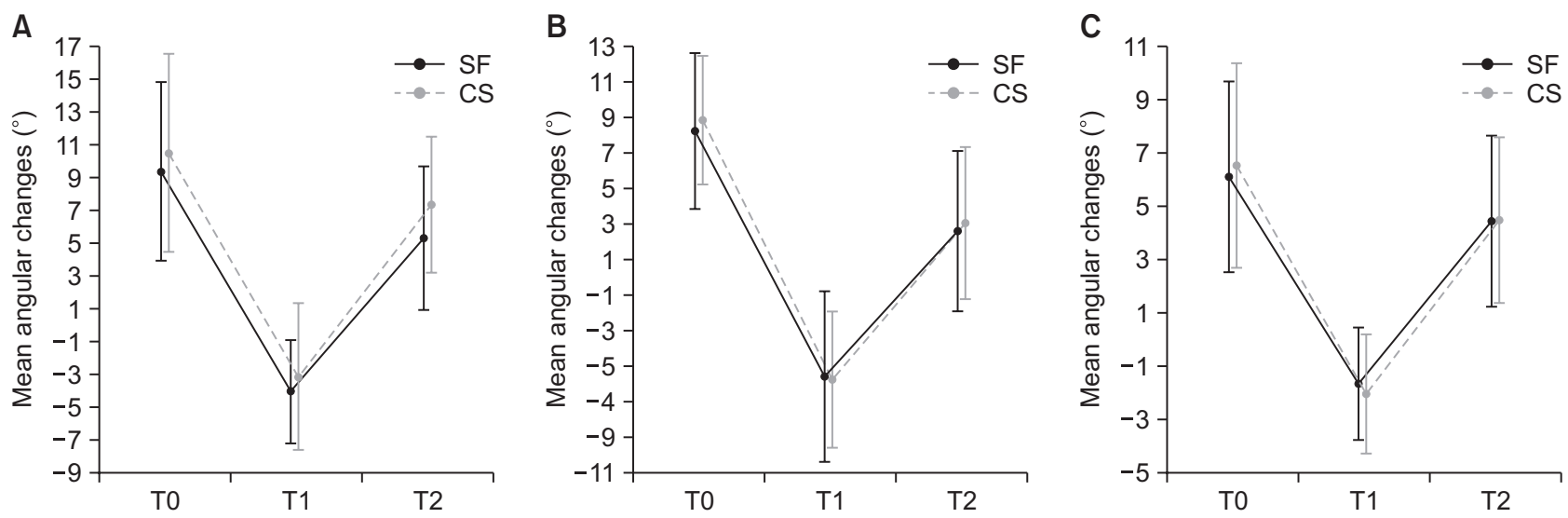

Figure 5. Evaluation of angular changes in the mandibular proximal segment before (T0), immediately after (T1), and 1 year after (T2) treatment with the surgery-first approach (SF) or the conventional orthognathic surgery approach (CS) using intraoral vertical ramus osteotomy. A, Horizontal change. B, Sagittal change. C, Coronal change. 
Table 6. Three-dimensional changes in CON from before surgery (T0) to 2 days (T1) and 1 year after surgery (T2) in the CS and SF groups

\begin{tabular}{|c|c|c|c|c|c|c|}
\hline \multicolumn{2}{|c|}{ Variable } & \multicolumn{2}{|c|}{ CS group } & \multicolumn{2}{|c|}{ SF group } & \multirow{2}{*}{$\begin{array}{c}\begin{array}{c}\text { Between } \\
\text { groups }\end{array} \\
\text { p-value } \\
\end{array}$} \\
\hline & & Mean \pm SD & $p$-value & Mean \pm SD & $p$-value & \\
\hline \multirow[t]{3}{*}{$\operatorname{CON}(\mathrm{x})(\mathrm{mm})$} & T1-T0 & $-0.6 \pm 0.9^{* * *, \dagger}$ & 0.000 & $-0.6 \pm 0.8^{* * *, \dagger}$ & 0.000 & 1.000 \\
\hline & $\mathrm{T} 2-\mathrm{T} 1$ & $0.2 \pm 0.6$ & 0.053 & $0.3 \pm 0.5^{* * *, \dagger}$ & 0.000 & 0.431 \\
\hline & T2-T0 & $-0.4 \pm 1.0^{*, \dagger}$ & 0.022 & $-0.3 \pm 0.8^{*, \dagger}$ & 0.023 & 0.630 \\
\hline \multirow[t]{3}{*}{$\mathrm{CON}(\mathrm{y})(\mathrm{mm})$} & T1-T0 & $1.1 \pm 1.3^{* * *, \dagger}$ & 0.000 & $1.8 \pm 1.5^{* * *, \dagger}$ & 0.000 & $0.034^{*}$ \\
\hline & $\mathrm{T} 2-\mathrm{T} 1$ & $-0.5 \pm 0.9^{* *, \dagger}$ & 0.002 & $-1.0 \pm 0.9^{* * *, \dagger}$ & 0.000 & $0.018^{*}$ \\
\hline & T2-T0 & $0.6 \pm 1.3^{* *, \dagger}$ & 0.009 & $0.8 \pm 1.1^{* * *, \dagger}$ & 0.000 & 0.470 \\
\hline \multirow[t]{3}{*}{$\mathrm{CON}(\mathrm{z})(\mathrm{mm})$} & T1-T0 & $2.6 \pm 1.3^{* * *, \dagger}$ & 0.000 & $2.5 \pm 1.4^{* * *, \dagger}$ & 0.000 & 0.749 \\
\hline & $\mathrm{T} 2-\mathrm{T} 1$ & $-2.1 \pm 0.9^{* * *, \dagger}$ & 0.000 & $-2.2 \pm 1.1^{* * *, \dagger}$ & 0.000 & 0.668 \\
\hline & T2-T0 & $0.5 \pm 1.0^{* *, \dagger}$ & 0.005 & $0.3 \pm 1.0$ & 0.065 & 0.387 \\
\hline
\end{tabular}

CON, Uppermost point on the condyle; CS, conventional orthognathic surgery; SF, surgery-first approach; SD, standard deviation; $\operatorname{CON}(\mathrm{x})$, medial/lateral movement relative to midsagittal plane: $(-)$ medial, $(+)$ lateral; $\mathrm{CON}(\mathrm{y})$, anteroposterior movement: (-) posterior movement, (+) anterior movement; $\operatorname{CON}(\mathrm{z})$, vertical movement: (-) upward, (+) downward. ${ }^{*} p<0.05,{ }^{* *} p<0.01,{ }^{* * *} p<0.001$.

Independent $t$-test or ${ }^{\dagger}$ paired $t$-test were performed.

$69.1 \%$ and $65.9 \%$ in the CS and SF groups, respectively, at 1 year after surgery. In the horizontal plane, the line passing through the medial condylar head point and lateral condylar head point rotated outward from MSP by $9.4^{\circ} \pm 5.4^{\circ}$ and $10.5^{\circ} \pm 6.0^{\circ}$, with recovery of $43.4 \%$ and $30.0 \%$, in the CS and SF groups, respectively.

The amount of anteroposterior movement of CON was significantly different between the two groups (Table 6), with anterior movement of $1.1 \pm 1.3 \mathrm{~mm}$ in the CS group and $1.8 \pm 1.5 \mathrm{~mm}$ in the SF group after surgery. At 1 year after surgery, the position was recovered by backward movement of $0.5 \pm 0.9 \mathrm{~mm}$ in the CS group and $1.0 \pm 0.9 \mathrm{~mm}$ in the SF group. There was no between-group difference in the other directions. The final position of the mandibular condyle was $0.4 \mathrm{~mm}$ medial, $0.6 \mathrm{~mm}$ anterior, and $0.5 \mathrm{~mm}$ inferior to the original position in the CS group, and $0.3 \mathrm{~mm}$ medial, $0.8 \mathrm{~mm}$ anterior, and $0.3 \mathrm{~mm}$ inferior in the SF group, with no significant between-group difference.

\section{DISCUSSION}

Displacement of the proximal segment could affect stability after mandibular setback surgery. ${ }^{5,6} \ln$ this study, positional changes in the mandibular proximal segment and condyles, which are surrounded by complex adjacent structures, were analyzed using advantages of the accuracy of the 3D CT image reconstruction and segmentation technique. ${ }^{13,14}$ Previous studies about SF have reported greater anterior relapse than that observed with CS, which is due to occlusal instability after the surgery. ${ }^{15}$ In cases of SF, the occlusal vertical dimension changes during postoperative orthodontic treatment. ${ }^{16,17}$ Previous studies on SF using SSRO reported counterclockwise mandibular autorotation with the center of rotation on the condylar head as the occlusal interference settled, which presented as a change in the ramal inclination. ${ }^{9,15}$ Unfortunately, most studies on mandibular positional changes after the SF have involved dealt with SSRO. ${ }^{10}$

IVRO differs from SSRO in terms of healing, which occurs once the unfixed cortical bones come in contact. ${ }^{18}$ The stability of IVRO is determined by the healing process of the two overlapped segments and ongoing repositioning of the condyles through early postoperative mobilization. ${ }^{19}$ Among the several advantages of IVRO, physiological positioning of the mandibular proximal segment through postoperative physiotherapy is clinically important. ${ }^{6}$ Previous studies regarding the stability of SF using IVRO primarily analyzed the distal segment using 2D lateral cephalograms. Kim et al. ${ }^{8}$ performed 2D analysis and reported anterior relapse of $0.6 \mathrm{~mm}$ and superior relapse of $2.9 \mathrm{~mm}$ at 1 year after SF using IVRO although there was no remarkable difference from the changes observed with CS. Choi et al. ${ }^{10}$ compared postoperative stability between CS using IVRO and SF using IVRO and reported that the distal segment moved upward by $1.9 \mathrm{~mm}$ at 1 year after surgery in the SF group. Moreover, the horizontal and vertical changes showed a linear correlation with the amount of setback.

In patients with Class 111 malocclusion, extrusion of the maxillary second molars is relatively common because of the lack of occlusion with the antagonist teeth. In patients who undergo SF, the vertical dimension is 
increased during setting of the surgical occlusion, generally because of these extruded maxillary molars. After surgery, the vertical dimension is decreased by direct intrusive mechanics or muscle force. ${ }^{16}$ In the present study, intrusion of the palatal cusps of the maxillary second molars, which induced occlusal changes, was observed in the SF group. Among the 20 patients in the SF group, 10 patients (50\%) required direct intrusion of the maxillary second molar using a skeletal anchorage system (SAS), while a multiloop edgewise arch wire with a reverse curve of Spee was used for three patients (15\%). For one patient (5\%), a step down bend was used for the bilateral maxillary first and second molar. These results imply the difference between IVRO and SSRO in terms of the change in the ramal inclination with occlusal changes. Evidence suggests that molar intrusion using SAS can induce counterclockwise rotation of the mandible by approximately $2.3^{\circ}$ to $3.9^{\circ} .^{17}$

In the present study, the pattern of change in the mandibular proximal segment in all planes and the position of CON was not significantly different between the CS and SF groups. When observed in the three planes, the proximal segment moved immediately after the surgery and was partially restored after 1 year, probably by rotation through the actions of the masseter and medial pterygoid muscles during physiotherapy. Because the distal segment moved backward and overlapped with the proximal segment during the surgery, it could not be completely restored to the original position. We speculate that a subperiosteal, cortical bone-derived, and endosseous callus was formed, remodeled during physiotherapy, and adapted at the new position. The final CON position in the SF group demonstrated that the condyles were set in the physiological position regardless of the postoperative occlusal changes; this verified that SF using IVRO results in stability after treatment.

In the present study, the change in the angle between PxP and MP was measured to evaluate the change in the positional relationship of the proximal and distal segments within the segmented mandible. The angle increased by $9.1^{\circ} \pm 4.5^{\circ}$ and $6.2^{\circ} \pm 5.2^{\circ}$ in the CS and SF groups, respectively, at 1 year after surgery. In the SF group, it appeared that adaptation occurred in the direction of upward movement of the front portion of the distal segment, thus resulting in a smaller angle between PxP and MP. This result implied that SF is accompanied by movement of the distal segment itself as well as tooth movement during postoperative orthodontic treatment.

We found that the anterior portion of the mandible moved upward by $0.9 \pm 1.0 \mathrm{~mm}$ in the SF group, where patients demonstrated bodily movement of the distal segment during the postoperative orthodontic treatment period. This was probably caused by the difference in the degree of instability of the preoperative occlusion. However, the degree of upward displacement was within the range that is considered normal after IVRO." Considering we analyzed data obtained 2 days and 1 year after surgery, we could not determine the exact time point at which the displacement took place. In studies where measurements were obtained at shorter time intervals using lateral cephalograms, it has been reported that movements of the segment occur within 6 months of the surgery. ${ }^{5,8,18}$ We speculate that the major dental changes occurred within 6 months after the surgery and were caused by the regional acceleration phenomenon, which results in a decrease in the vertical dimension; the movement of the distal segment may also have occurred during this period..$^{20,21} \ln$ accordance with the skeletal and dental changes, overjet decreased and overbite increased in our SF group.

On the basis of our results, it is suggested that surgeons should consider the superior relapse tendency of the mandible when planning treatment with SF, while orthodontists should observe whether the rotation fulcrum of the distal segment moves to an unintended location during the postoperative orthodontic phase.

Because the observation period in the present study was only 1 year, studies with longer follow-up durations are required. In addition, a study with an additional detailed classification of the subjects by the degree of vertical dimensional changes in a larger sample would make a valuable contribution to research regarding the stability of SF.

\section{CONCLUSION}

In summary, the present results suggest that positional changes in the mandibular proximal segment were similar between SF using IVRO and CS using IVRO in patients with skeletal Class 111 malocclusion, regardless of differences in postoperative skeletal and dental changes in the maxillomandibular complex between the two groups. If active physiotherapy is performed, the proximal segment can be adapted in the physiological location regardless of the postoperative occlusal changes. With SF, there is movement of the distal segment itself as well as tooth movement during postoperative orthodontic treatment; therefore, close observation is necessary in order to prevent the formation of rotation fulcrum in an undesired location.

\section{CONFLICTS OF INTEREST}

No potential conflict of interest relevant to this article was reported. 


\section{REFERENCES}

1. Jacobs JD, Sinclair PM. Principles of orthodontic mechanics in orthognathic surgery cases. Am J Orthod 1983;84:399-407.

2. Nagasaka H, Sugawara J, Kawamura H, Nanda R. "Surgery first" skeletal Class 111 correction using the Skeletal Anchorage System. J Clin Orthod 2009;43:97-105.

3. Kim CS, Lee SC, Kyung HM, Park HS, Kwon TG. Stability of mandibular setback surgery with and without presurgical orthodontics. J Oral Maxillofac Surg 2014;72:779-87.

4. Nihara J, Takeyama M, Takayama Y, Mutoh Y, Saito 1. Postoperative changes in mandibular prognathism surgically treated by intraoral vertical ramus osteotomy. Int J Oral Maxillofac Surg 2013;42:62-70.

5. Ohba S, Nakao N, Awara K, Tobita T, Minamizato $\mathrm{T}$, Kawasaki $\mathrm{T}$, et al. The three-dimensional assessment of dynamic changes of the proximal segments after intraoral vertical ramus osteotomy. Cranio 2015;33:276-84.

6. Jung HD, Jung YS, Park JH, Park HS. Recovery pattern of mandibular movement by active physical therapy after bilateral transoral vertical ramus osteotomy. J Oral Maxillofac Surg 2012;70:e431-7.

7. Bell WH, Yamaguchi Y, Poor MR. Treatment of temporomandibular joint dysfunction by intraoral vertical ramus osteotomy. Int J Adult Orthodon Orthognath Surg 1990;5:9-27.

8. Kim JY, Jung HD, Kim SY, Park HS, Jung YS. Postoperative stability for surgery-first approach using intraoral vertical ramus osteotomy: 12 month follow-up. Br J Oral Maxillofac Surg 2014;52:539-44.

9. Ko EW, Lin SC, Chen YR, Huang CS. Skeletal and dental variables related to the stability of orthognathic surgery in skeletal Class 111 malocclusion with a surgery-first approach. J Oral Maxillofac Surg 2013;71:e215-23.

10. Choi SH, Hwang CJ, Baik HS, Jung YS, Lee KJ. Stability of pre-orthodontic orthognathic surgery using intraoral vertical ramus osteotomy versus conventional treatment. J Oral Maxillofac Surg 2016; 74:610-9.

11. Jung HD, Jung YS, Kim SY, Kim DW, Park HS. Postoperative stability following bilateral intraoral vertical ramus osteotomy based on amount of setback. Br J Oral Maxillofac Surg 2013;51:822-6.
12. Park SH, Yu HS, Kim KD, Lee KJ, Baik HS. A proposal for a new analysis of craniofacial morphology by 3-dimensional computed tomography. Am J Orthod Dentofacial Orthop 2006;129:600.e23-34.

13. Kang SH, Kim MK, You TK, Lee JY. Modification of planned postoperative occlusion in orthognathic surgery, based on computer-aided design/computeraided manufacturing-engineered preoperative surgical simulation. J Oral Maxillofac Surg 2015;73:13451.

14. Uribe F, Janakiraman N, Shafer D, Nanda R. Threedimensional cone-beam computed tomographybased virtual treatment planning and fabrication of a surgical splint for asymmetric patients: surgery first approach. Am J Orthod Dentofacial Orthop 2013;144:748-58.

15. Baek SH, Ahn HW, Kwon YH, Choi JY. Surgery-first approach in skeletal class 111 malocclusion treated with 2-jaw surgery: evaluation of surgical movement and postoperative orthodontic treatment. J Craniofac Surg 2010;21:332-8.

16. Lee J, Kim Yl, Hwang DS, Kim KB, Park SB. Effect of occlusal vertical dimension changes on postsurgical skeletal changes in a surgery-first approach for skeletal Class 111 deformities. Am J Orthod Dentofacial Orthop 2014;146:612-9.

17. Alsafadi AS, Alabdullah MM, Saltaji H, Abdo A, Youssef M. Effect of molar intrusion with temporary anchorage devices in patients with anterior open bite: a systematic review. Prog Orthod 2016;17:9.

18. Arimoto S, Hasegawa T, Kaneko K, Tateishi C, Furudoi S, Shibuya Y, et al. Observation of osseous healing after intraoral vertical ramus osteotomy: focus on computed tomography values. J Oral Maxillofac Surg 2013;71:1602.e1-10.

19. Ghali GE, Sikes JW Jr. Intraoral vertical ramus osteotomy as the preferred treatment for mandibular prognathism. J Oral Maxillofac Surg 2000;58:313-5.

20. Wilcko WM, Wilcko T, Bouquot JE, Ferguson DJ. Rapid orthodontics with alveolar reshaping: two case reports of decrowding. Int J Periodontics Restorative Dent 2001;21:9-19.

21. Wilcko MT, Wilcko WM, Pulver JJ, Bissada NF, Bouquot JE. Accelerated osteogenic orthodontics technique: a 1-stage surgically facilitated rapid orthodontic technique with alveolar augmentation. J Oral Maxillofac Surg 2009;67:2149-59. 